Check for updates

Cite this: RSC Adv., 2019, 9, 3938

\title{
Insight into the effect of quinic acid on biofilm formed by Staphylococcus aureus
}

\author{
Jin-Rong Bai, (D) Yan-Ping Wu, (D) Grosu Elena, Kai Zhong* and Hong Gao
}

The biofilm formation of Staphylococcus aureus on food contact surfaces is the main risk of food contamination. In the present study, we firstly investigated the inhibitory effect of quinic acid (QA) on biofilm formed by $S$. aureus. Crystal violet staining assay and microscopy analysis clearly showed that QA at sub-MIC concentrations was able to significantly reduce the biofilm biomass and cause a collapse on biofilm architecture. Meanwhile, fibrinogen binding assay showed that QA had obviously effect on the $S$. aureus bacteria adhesion. XTT reduction assay and confocal laser scanning microscopic images revealed that QA significantly decreased metabolic activity and viability of biofilm cells. In addition, qRT-PCR analysis explored the potential inhibitory mechanism of QA against biofilm formation, which indicated that QA significantly repressed the gene sarA and activated the gene agrA. Moreover, QA exhibited a highly ability to reduce the number of sessile $S$. aureus cells adhered on the stainless steel. So, it was suggested that QA could be used as a promising antibiofilm agent to control biofilm formation of $S$. aureus.

Received 4th November 2018 Accepted 22nd January 2019

DOI: 10.1039/c8ra09136f

rsc.li/rsc-advances foodborne pathogens contamination. In the United States, organic acids have been approved for use to prevent pathogen contamination in the meat decontamination area. ${ }^{\mathbf{1 0}}$ Some of them have been reported to exhibit the excellent inhibitory activity against $S$. aureus biofilm formation, consisting of gallic acid, ${ }^{\mathbf{1}}$ citric acid, ${ }^{\mathbf{1 1}}$ ellagic acid, ${ }^{\mathbf{1 2}}$ ginkgolic acid, ${ }^{\mathbf{1 3}}$ caffeic acid and chlorogenic acid. ${ }^{\mathbf{1 4}}$ Despite the excellent ability of these antibiofilm agents for inhibiting biofilm formation has been discovered, the molecular mechanism of the inhibitory action remains unclear and challenging. From this perspective, it is necessary to explore the inhibitory action mechanism of organic acids.

Quinic acid (QA), widely spread in many plants, is an important organic acid with many biological activities, including antioxidant, antimutagenic and anti-inflammatory activities. ${ }^{\mathbf{1 5 , 1 6}}$ Although QA has been proved to have the excellent antibacterial activity against $S$. aureus through damaging the cell membrane and interfering with normal functions of cells in our previous study, ${ }^{17,18}$ its inhibitory effect against $S$. aureus biofilm formation is not clear. Therefore, in the present study, we firstly reported the capacity of QA to inhibit biofilm formation of $S$. aureus and explored its potential mechanism.

\section{Materials and methods}

\subsection{Chemicals, bacteria strain, and culture conditions}

QA ( $\geq 98 \%)$ was purchased from the Aladdin Industrial Corporation (Shanghai, China). QA was dissolved in distilled water and diluted with the corresponding medium for the assays. The standard bacterial strain S. aureus ATCC 29213 (ATCC, Arlington, Virginia, USA) was used in the present study for its ability to form
College of Light Industry, Textile and Food Engineering and Healthy Food Evaluation Research Center, Sichuan University, Chengdu 610065, P. R. China.E-mail: eric211@ 163.com; Fax: +86 028 85405137; Tel: +8602885405236 
biofilms. The bacterial cells were shaken at $37{ }^{\circ} \mathrm{C}$ for $10 \mathrm{~h}$ in tryptone soy broth (TSB) supplemented with $1 \%$ glucose to obtain logarithmic phase cells for biofilm assay. The minimum inhibitory concentration (MIC) of QA against S. aureus ATCC 29213 was detected to be $5.0 \mathrm{mg} \mathrm{mL}{ }^{-1} .^{17}$

\subsection{Biofilm formation}

The biofilm of $S$. aureus ATCC 29213 was prepared in a 96-well microtitre plate by the previous method with a slight modification. ${ }^{19}$ In brief, logarithmic phase $S$. aureus cells were diluted with TSB with $1 \%$ glucose to obtain a bacterial suspension of $1 \times 10^{6}$ CFU $\mathrm{mL}^{-1}$. Then, $100 \mu \mathrm{L}$ of the bacterial suspension was dispensed into each well of a microtitre plate in the presence of sub-MIC concentrations of QA. The negative control was the TSB with $1 \%$ glucose. All of wells were seeded in triplicate. The plate was incubated at $37^{\circ} \mathrm{C}$ for $24 \mathrm{~h}$ without shaking to form the oneday-old biofilm.

\subsection{Assessment of growth inhibition and biofilm biomass}

After one-day-old biofilm formation, we measured absorbance values at $600 \mathrm{~nm}$ using a microplate reader (Spectra MAX-190, Molecular Devices Co., Sunnyvale, CA, USA) to evaluate the effect of QA on the planktonic bacterial growth according the previous report. ${ }^{20}$ The planktonic cells were discarded from the wells, and then the wells were gently washed twice with PBS (0.01 M, pH 7.2). Subsequently, $200 \mu \mathrm{L}$ of $0.4 \%$ crystal violet solution was added to the wells to stain the adherent sessile cells for $5 \mathrm{~min}$. The stained biofilm cells were washed twice with distilled water and dissolved in 200 $\mu \mathrm{L}$ of $20 \%$ glacial acetic acid. After $30 \mathrm{~min}$, the biofilm biomass was quantified by measuring the optical density at $570 \mathrm{~nm}$. The reduction percentage of growth or biofilm was shown by using the following formula (Sivaranjani et al., 2016)..$^{21}$

$$
\begin{aligned}
& \text { Reduction percentage }=[(\text { Control OD } 600 / 570 \mathrm{~nm} \\
& \left.\left.- \text { treated } \mathrm{OD}_{600 / 570 \mathrm{~nm}}\right) / \text { control } \mathrm{OD}_{600 / 570 \mathrm{~nm}}\right] \times 100
\end{aligned}
$$

\subsection{Scanning electron microscopic (SEM)}

In order to visualize the inhibition of QA on the biofilm formation of $S$. aureus, SEM images were performed using a scanning electron microscope (SU3500, Hitachi, Japan) according to the previously reported method with minor modifications. ${ }^{14}$ In brief, $500 \mu \mathrm{L}$ of QA $(0.3125,0.625,1.25 \mathrm{mg}$ $\mathrm{mL}^{-1}$ ) was added into the wells of a 24 -well microplate containing sterile round glass slides $(\varnothing 14 \mathrm{~mm})$. Then, $500 \mu \mathrm{L}$ of cell suspension at a density of $1 \times 10^{6} \mathrm{CFU} \mathrm{mL}^{-1}$ was added into the wells. After incubation at $37{ }^{\circ} \mathrm{C}$ for $24 \mathrm{~h}$, the glass slides were gently taken out, fixed in $2.5 \%$ glutaraldehyde at $4{ }^{\circ} \mathrm{C}$ for $3 \mathrm{~h}$, and then gently washed once with PBS (0.01 M, pH 7.2). Subsequently, biofilm samples were dehydrated in a sequence of ethanol, dried with critical point drier, and coated with gold prior to observation.

\subsection{Fibrinogen binding assay}

Fibrinogen binding assay was performed according to the previously reported method with little modifications. ${ }^{20}$ In brief, $1 \mathrm{~mL}$ of logarithmic phase $S$. aureus cells $\left(1 \times 10^{6} \mathrm{CFU}\right.$ $\mathrm{mL}^{-1}$ ) with different concentrations of QA were co-cultured at $37{ }^{\circ} \mathrm{C}$ with shaking at $120 \mathrm{rpm}$ for $5 \mathrm{~h}$. The bacterial cells were collected by centrifugation at $3000 \mathrm{rpm}$ for $5 \mathrm{~min}$, and suspended in PBS (0.01 M, pH 7.2). Then, $100 \mu \mathrm{L}$ of the bacterial suspension was dispensed into each well of a 96well microtitre plate coated with fibrinogen (incubated with $20 \mu \mathrm{g} \mathrm{mL}{ }^{-1}$ of bovine fibrinogen at $4{ }^{\circ} \mathrm{C}$ for $12 \mathrm{~h}$ ) and further incubated at $37^{\circ} \mathrm{C}$. After $1 \mathrm{~h}$, the wells were washed once with PBS (0.01 M, pH 7.2) and fixed with $25 \%$ formaldehyde for 30 min. Finally, the biomass of adherent bacteria were investigated by using the crystal violet staining assay as described above method of 2.3. The relative percentage of adhesion was calculated according to the following formula.

Relative $\%$ adhesion $=$ Treated $\mathrm{OD}_{570 \mathrm{~nm}} /$ control $\mathrm{OD}_{570 \mathrm{~nm}} \times 100$

\subsection{Assessment of metabolic activity of $S$. aureus cells in biofilm}

The metabolic activity changes of $S$. aureus biofilm cells induced by QA were detected using 2,3-bis (2-methoxy-4-nitro-5-sulfophenyl)-2H-tetrazolium-5-carboxanilide sodium salt (XTT) reduction assay as described previously method with minor modifications. ${ }^{22}$ After incubation with QA and washing progress, biofilm cells in the microplate were further incubated with 120 $\mu \mathrm{L}$ of the mixed solution of XTT (Sigma Aldrich Co., St. Louis, USA) and phenazine methosulphate (Sigma Aldrich Co., St. Louis, USA) dissolved in PBS (0.01 M, pH 7.2). The final concentration of XTT in each well was set at $100 \mu \mathrm{g} \mathrm{mL} \mathrm{m}^{-1}$ and phenazine methosulphate was $10 \mu \mathrm{g} \mathrm{mL}^{-1}$. Following incubation in the darkness at $37^{\circ} \mathrm{C}$ for $3 \mathrm{~h}$, the biofilm metabolic activity was determined through the measurement of the absorbance value at $492 \mathrm{~nm}$ in each well using the above microplate reader.

\subsection{Confocal laser scanning microscopic (CLSM)}

The biofilm cell viability changes induced by QA were determined using LIVE/DEAD BacLight bacterial viability kit (Life Technologies, MA, USA) according to the manufacturer's instructions. Briefly, the biofilms in the presence and absence of QA were grown on the glass slides as described above method. After incubation and washing procedures, the biofilms on slides were stained with $500 \mu \mathrm{L}$ of a combined dye solution of SYTO 9 and propidium iodide (PI) diluted with PBS (0.01 M, pH 7.2) keeping a final concentration of $5 \mu \mathrm{M}$ of SYTO 9 and $30 \mu \mathrm{M}$ of PI. Following treatment at $25{ }^{\circ} \mathrm{C}$ for $15 \mathrm{~min}$ in the darkness, the stained biofilms were observed by a confocal laser scanning microscope (SP8, Leica, Germany).

\subsection{Isolation of RNA and qRT-PCR analysis}

The changes of the transcription levels of the related genes during $S$. aureus biofilm formation were evaluated by qRT-PCR 
analysis. S. aureus cells were performed according to the previously reported method with minor modifications. ${ }^{23}$ Briefly, $1 \mathrm{~mL}$ of logarithmic phase $S$. aureus cells $\left(1 \times 10^{6} \mathrm{CFU} \mathrm{mL}^{-1}\right)$ were cultured at $37{ }^{\circ} \mathrm{C}$ with shaking at $120 \mathrm{rpm}$. After $3 \mathrm{~h}$, QA was added to a concentration of $1.25 \mathrm{mg} \mathrm{mL}^{-1}$ and the bacterial suspensions were further incubated for $5 \mathrm{~h}$. Bacterial suspensions were then centrifuged at $3000 \mathrm{rpm}$ for $5 \mathrm{~min}$. RNA from $S$. aureus cells was isolated using UNIQ-10 Trizol (Sangon Biotech, Shanghai, China) according to the manufacturer's protocol. The isolated RNAs were reverse-transcribed into cDNA by using the RevertAid Premium Reverse Transcriptase (Thermo Fisher Scientific, MA, USA). Continuously, the expressions of the 5 selected genes by qRT-PCR were measured. The 5 selected genes were polysaccharide intercellular adhesion locus genes (icaA, $i c a R)$, RNA polymerase sigma factor $(\operatorname{sig} B)$, quorum sensing gene (agrA), and staphylococcal accessory regulator A (sarA), respectively. Gene-specific primers and 16s rRNA housekeeping gene primer were presented in Table $1 .{ }^{23}$ qRT-PCR was determined by using the 2xSG Fast qPCR Master Mix Kit (Sangon Biotech, Shanghai, China) and StepOne Real-Time PCR system (Applied Biosystems, CA, USA).

\subsection{Stainless steel model assay}

Biofilm assay on stainless steel was performed as previously described method with minor modifications. ${ }^{6}$ AISI 304 grade annealed stainless steel was used for making coupons. Stainless steel coupons $(2 \mathrm{~cm} \times 2 \mathrm{~cm} \times 1 \mathrm{~mm}$ thickness $)$ were cleaned with a neutral detergent followed by distilled water, autoclaved at $121{ }^{\circ} \mathrm{C}$ for $20 \mathrm{~min}$, and dried at $80{ }^{\circ} \mathrm{C}$ prior to use. An amount of $10 \mathrm{~mL}$ of bacterial suspensions of logarithmic phase $S$. aureus

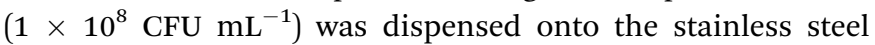
coupons submerged in separate tubes at $37{ }^{\circ} \mathrm{C}$ for $2 \mathrm{~h}$. Continuously, the steel coupons were gently washed with $0.1 \%$ peptone water to remove planktonic cells, and then immersed in $10 \mathrm{~mL}$ of QA solutions (dissolved in $0.1 \%$ peptone water) at the concentrations of $5,10,15 \mathrm{mg} \mathrm{mL}{ }^{-1}$, respectively, for $10 \mathrm{~min}$. The negative control was performed with $0.1 \%$ peptone water. After washed with $0.1 \%$ peptone water to remove excess QA, each steel coupon was immersed in $10 \mathrm{~mL}$ of $0.1 \%$ peptone water and sonicated at $55 \mathrm{kHz}$ for $10 \mathrm{~min}$ in a bath sonicator

Table 1 Primer sequences for quantitative qRT-PCR

\begin{tabular}{|c|c|}
\hline Gene & Primer \\
\hline icaA & Forward 5 -CTG GCG CAG TCA ATA CTA TTT CGG GTG TCT- $3^{\prime}$ \\
\hline icaR & Forward 5' TGC TTT CAA ATA CCA ACT TTC AAG A $3^{\prime}$ \\
\hline & Reverse $5^{\prime}$ ACG TTC AAT TAT CTA ATA CGC CTG A $3^{\prime}$ \\
\hline $\operatorname{sig} B$ & $\begin{array}{l}\text { Forward 5'-AAG TGA TTC GTA AGG ACG TCT- } 3^{\prime} \\
\text { Reverse } 5^{\prime} \text {-TCG ATA ACT ATA ACC AAA GCC T- } 3^{\prime}\end{array}$ \\
\hline $\operatorname{agr} A$ & $\begin{array}{l}\text { Forward 5'-TGA TAA TCC TTA TGA GGT GCT T-3' } \\
\text { Reverse } 5^{\prime} \text {-CAC TGT GAC TCG TAA CGA AAA-3' }\end{array}$ \\
\hline sarA & $\begin{array}{l}\text { Forward 5'-CAA ACA ACC ACA AGT TGT TAA AGC-3' } \\
\text { Reverse } 5^{\prime} \text {-TGT TTG CTT CAG TGA TTC GTT T- } 3^{\prime}\end{array}$ \\
\hline $16 s$ & Forward 5'-ACTCCTACGGGAGGCAGCAG-3' \\
\hline rRNA & Reverse $5^{\prime}$-ATTACCGCGGCTGCTGG-3' \\
\hline
\end{tabular}

(AS3120B, Aote Saiensi Instrument Co., Tianjin, China). The viable bacterial counts in $0.1 \%$ peptone water from each tube were detected after serial dilution and spread on nutrient agar plates. After incubation of the inoculated nutrient agar plates at $37{ }^{\circ} \mathrm{C}$ for $24 \mathrm{~h}$, the density of biofilm cells was calculated according to the following formula.

$\log \mathrm{CFU} \mathrm{cm} \mathrm{cm}^{-2}=\log \left[\mathrm{CFU} \mathrm{mL} \mathrm{mL}^{-1} \times 10 /\right.$ steel coupon area $\left.\left(\mathrm{cm}^{2}\right)\right]$

\subsection{Statistical analysis}

All experiments were performed in independent triplicate. Statistical analyses were conducted with the SPSS software (version 20.0; SPSS, I., Chicago, IL). Data differences were considered statistically significant at $P<0.05$.

\section{Results}

\subsection{QA inhibited the biofilm formation of $S$. aureus without affecting the bacterial growth}

The biofilm biomass assay using crystal violet staining is a rapid and convenient method for testing the biofilm formation. To evaluate the effect of QA on $S$. aureus biofilm formation, $S$. aureus and QA at sub-MICs were co-cultured using the microdilution method. As shown in Fig. 1, when treated with QA ranging from 0.3125 to $1.25 \mathrm{mg} \mathrm{mL}^{-1}$ for $24 \mathrm{~h}$, the biofilm biomass of $S$. aureus was significantly reduced ranging from $55 \%$ to $70 \%$ compared with the control biofilm $(P<0.01)$. To determine whether the effect of QA on biofilm was dependent on the growth inhibition of planktonic bacteria, the growth of $S$. aureus was detected by measuring absorbance values at $600 \mathrm{~nm}$ after incubation for $24 \mathrm{~h}$. When treated with QA at $1.25 \mathrm{mg}$ $\mathrm{mL}^{-1}$, the growth of $S$. aureus was decrease slightly by approximately $20 \%$ in (Fig. 1). So, it was suggested that QA did not influence $(P>0.05)$ the growth of $S$. aureus at its sub-MICs but

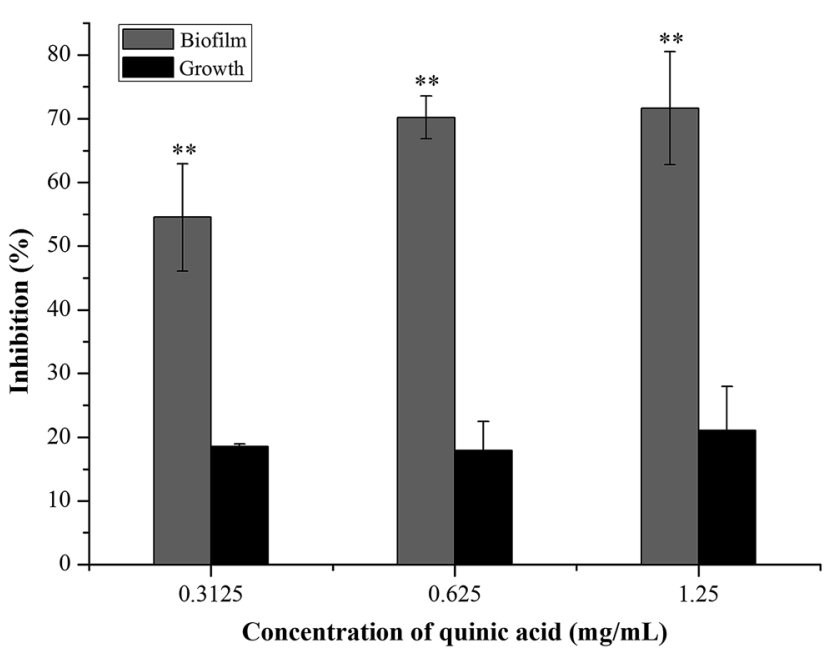

Fig. 1 Effect of quinic acid on the planktonic growth and biofilm biomass of S. aureus ATCC 29213. Data were expressed as mean \pm standard deviation $(n=3)$. $* * P<0.01$, compared with control. 

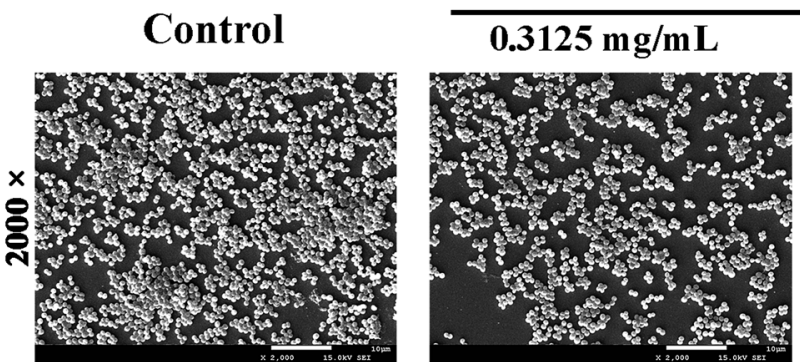

Quinic acid
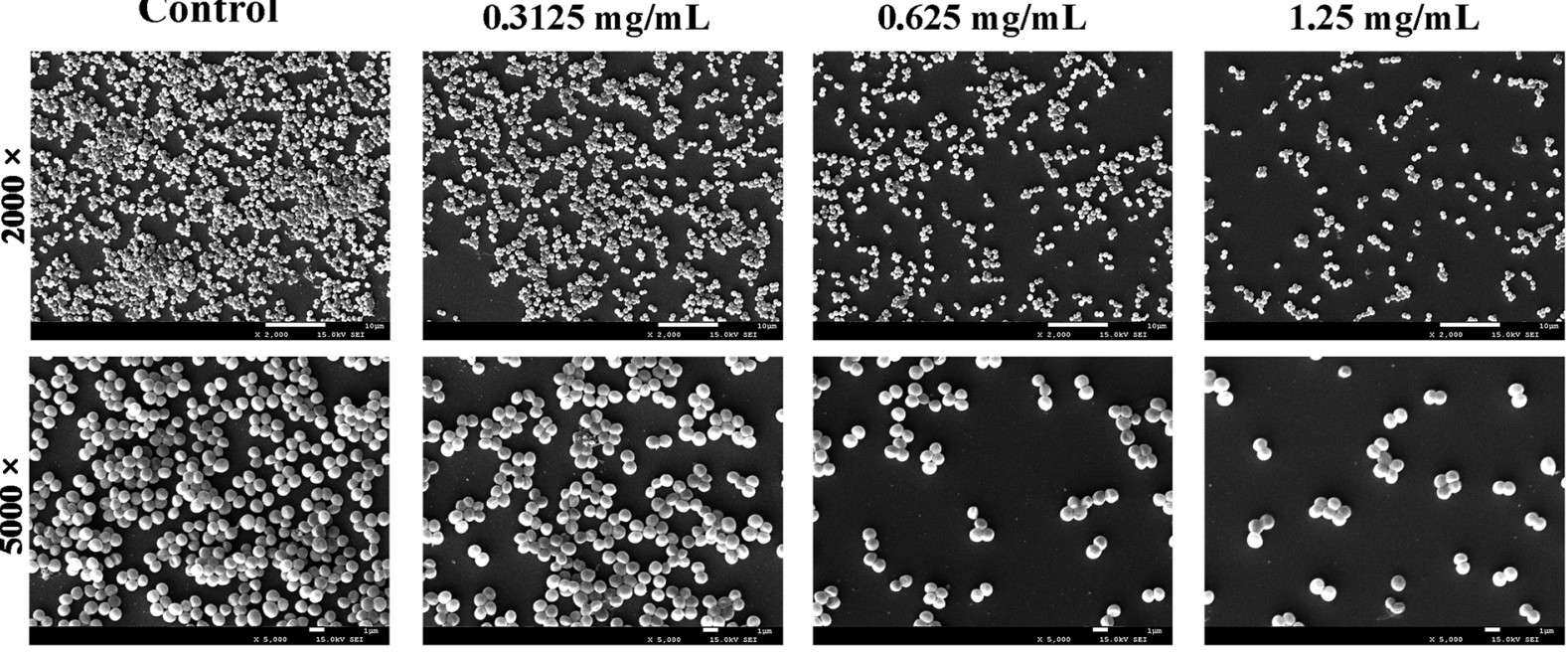

Fig. 2 Microscopic visualization of inhibitory activity of quinic acid against S. aureus ATCC 29213 biofilm formation by scanning electron micrographs at 2000 and 5000 times magnification, respectively.

could significantly inhibit the formation of $S$. aureus biofilm $(P<$ $0.01)$.

\subsection{Biofilms treated with QA had loosely extracellular polymeric matrix}

To visualize the morphology and ultrastructural structure of $S$. aureus biofilms treated with QA, the distinctions were observed in biofilm architecture at high resolution using SEM at 2000 and 5000 times magnification (Fig. 2). Biofilms exhibited monolayer and slackened cell cluster in the presence of $0.3125 \mathrm{mg} \mathrm{mL}^{-1}$ of QA. When biofilms were treated with higher concentration of QA, there were fewer clumps of attached microcolonies and even individual cells on the glass slides. In comparison, the untreated biofilm presented continuous clumps and large aggregates of cells.

\subsection{QA decreased the adhesion of $S$. aureus to fibrinogen}

Fibrinogen, a kind of plasma protein, can be used as a substrate for staphylococcal adhesion. ${ }^{24}$ In order to examine the effect of QA on $S$. aureus adhesion, fibrinogen binding assay was conducted using microtitre plate coated with fibrinogen. The result was shown in Fig. 3. Compared to the control group, the relative percentage adhesion was significantly $(P<0.01)$ decreased after treatment with QA at $0.3125,0.625$ and $1.25 \mathrm{mg} \mathrm{mL}^{-1}$. The results suggested that QA reduced the $S$. aureus bacteria adhesion to fibrinogen.

\subsection{QA decreased metabolic activity and viability of $S$. aureus biofilm cells}

XTT reduction assay was carried out to evaluate the effect of QA on the metabolic activity of $S$. aureus biofilm cells. The absorbance values at $492 \mathrm{~nm}$ can indirectly reflect the total metabolic activity of cells, as the metabolically active cells are able to decrease the XTT into orange colored water soluble formazan. ${ }^{21}$ As shown in Fig. 4, QA significantly reduced the metabolic activity of $S$. aureus biofilm cells $(P<0.01)$. The absorbance values at $492 \mathrm{~nm}$ of $S$. aureus biofilm cells were detected to be $0.22 \pm 0.01,0.22 \pm 0.02$ and $0.18 \pm 0.05$ in the presence of QA at $0.3125,0.625$ and $1.25 \mathrm{mg} \mathrm{mL}{ }^{-1}$, respectively, whereas the absorbance value of the untreated control cells was $0.27 \pm 0.02$.

The LIVE/DEAD BacLight bacterial viability kit and CLSM were also used to detect whether QA can interfere with the viability of cells in the $S$. aureus biofilm. SYTO 9, a kind of nucleic acid dye, can penetrate both live and damaged bacterial cells, and emits strong green fluorescence. On the other hand, another kind of nucleic acid dye PI is only able to penetrate damaged or dead bacterial cells, and emits red fluorescence. ${ }^{8}$ The CLSM images of bacteria labeled with SYTO 9 and PI at 620 times magnification were presented in Fig. 4B and C. Obviously, the CLSM image of the negative control samples (Fig. 4B) with no QA treatment revealed that the formation of a dense biofilm

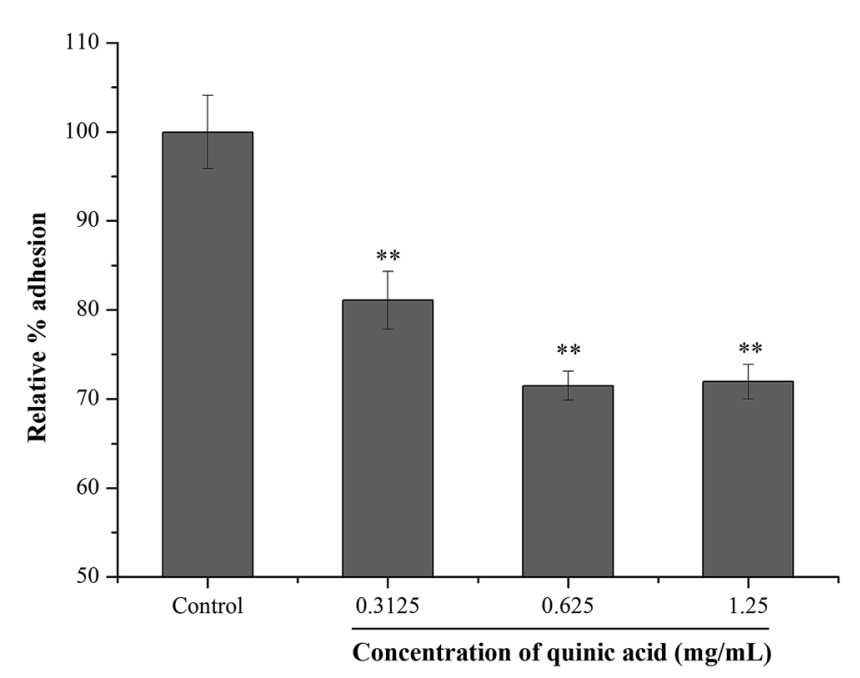

Fig. 3 Effect of quinic acid on the relative percentage adhesion of $S$. aureus ATCC 29213 to fibrinogen. Data were expressed as mean \pm standard deviation $(n=3)$. $* * P<0.01$, compared with control. 

(C).
A

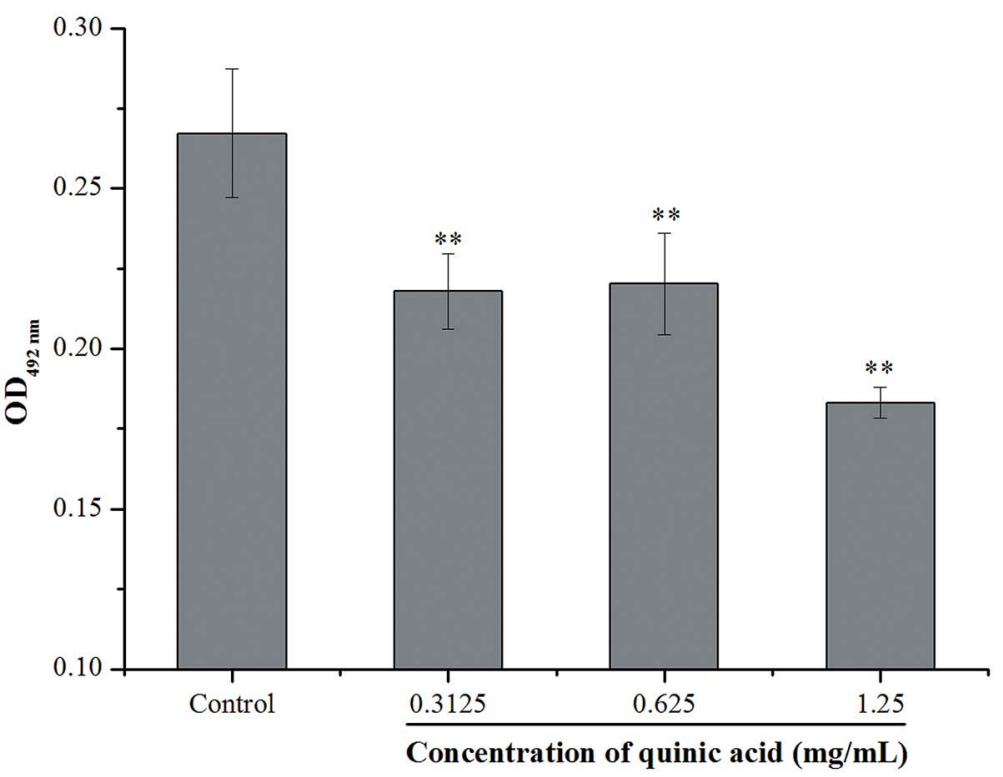

B

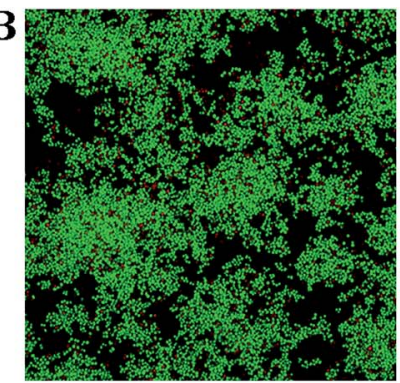

C

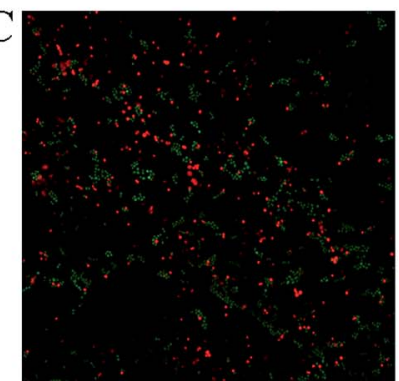

Fig. 4 Effect of quinic acid on the metabolic activity of S. aureus ATCC 29213 biofilm cells (A). Data were expressed as mean \pm standard deviation $(n=3) . * P<0.05, * * P<0.01$, compared with control. The confocal laser scanning microscopic images at 620 times magnification of $S$. aureus ATCC 29213 biofilm stained with LIVE/DEAD BacLight bacterial viability kit for untreated cells (B) and treatment with $1.25 \mathrm{mg} \mathrm{mL}^{-1}$ of quinic acid

viewed as almost green cells, and the green fluorescence intensity was strong, indicating that the untreated cells were viable and active. In comparison, a significant reduction of the green fluorescence was observed on the cells treated with QA at $1.25 \mathrm{mg} \mathrm{mL} \mathrm{L}^{-1}$ (Fig. 4C), and the green fluorescence intensity was very weak. Furthermore, the red fluorescence intensity was enhanced in Fig. 4C compared to the control, suggesting that the biofilm treated with $1.25 \mathrm{mg} \mathrm{mL}^{-1}$ of QA was composed of damaged and dead cells.

\subsection{QA modulated the expression of related genes during $S$. aureus biofilm formation}

To further investigate the molecular mechanism of biofilm formation inhibition of QA, qRT-PCR was performed to detect the expression of several genes related to the biofilm formation. As shown in Fig. $5 \mathrm{~A}$, when $1.25 \mathrm{mg} \mathrm{mL}^{-1}$ of QA was used, the gene sarA which encodes staphylococcal accessory regulator $\mathrm{A}$ (SarA) was significantly repressed by $76 \%(P<0.01)$. The polysaccharide intercellular adhesion locus gene icaA was activated, whereas the ica operon repressor icaR was inhibited by $47 \%$ compared to control. In addition, QA treatment significantly upregulated agrA and $\operatorname{sig} B(P<0.05)$, which encode quorum sensing gene regulator (AgrA) and RNA polymerase sigma factor (SigB), respectively.

\subsection{QA inhibited the $S$. aureus cell adhered to stainless steel}

To investigate the effect of QA on the $S$. aureus cells adhered to stainless steel, initial planktonic populations of approximately $8.0 \log \mathrm{CFU} \mathrm{mL} \mathrm{mL}^{-1}$ of $S$. aureus cells were allowed to adhere on the stainless steel for $2 \mathrm{~h}$. After bacterial adhesion to stainless steel, the inhibitory activity of QA at different concentrations was evaluated using 10 min contact time. As shown in Fig. 6, the initial population of the adherent cells in S. aureus biofilm on the stainless steel was $5.82 \log \mathrm{CFU} \mathrm{cm}{ }^{-1} .{ }^{2}$ After 10 min contact time, treatment with QA at 5,10 and $15 \mathrm{mg} \mathrm{mL}^{-1}$ significantly reduced the populations of the adherent cells by 1.05, 1.47 and $1.77 \log \mathrm{CFU} \mathrm{cm}{ }^{-1},{ }^{2}$ respectively $(P<0.01)$.

\section{Discussion}

Currently, the majority of microbial contamination in the food industry is attributed to biofilm formation and growth on food plants or during the processing processes. ${ }^{9}$ The biofilm cells are highly tolerant to harmful factors in the environment, such as desiccation, antimicrobial agents and the body's immune system, causing large economic losses., ${ }^{92}$ Along with economic loss problems, biofilm formation on food contact surfaces possesses a high health risk to consumers. ${ }^{6}$ Therefore, a highefficiency way to prevent biofilm formation and eradicate the biofilm adhesion still remains challenging. The present study focused on an antibiofilm agent QA that could effectively inhibit biofilm formation of $S$. aureus without exerting any pressure over the planktonic cell growth.

Our results of biofilm biomass measurement showed that QA at sub-MICs significantly inhibited the biofilm formation $(P$ $<0.01$ ) without interfering with the planktonic growth of $S$. aureus $(P>0.05)$. It revealed that the reduction in biofilm biomass was mainly attributed to the antibiofilm potential of QA rather than the decreased growth rate of $S$. aureus cells. Several studies have proved that organic acids had antibiofilm activity against $S$. aureus. For instance, citric acid, could significantly inhibit the biofilm formation of $S$. aureus. ${ }^{11}$ In addition, gallic acid, caffeic acid and chlorogenic acid had obviously inhibitory action on the biofilm formation of $S$. 
A

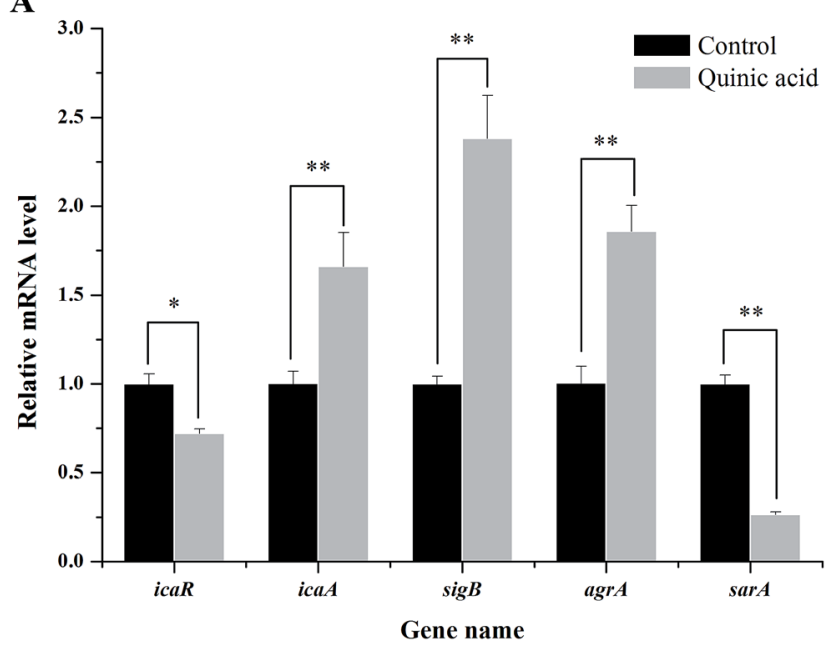

B

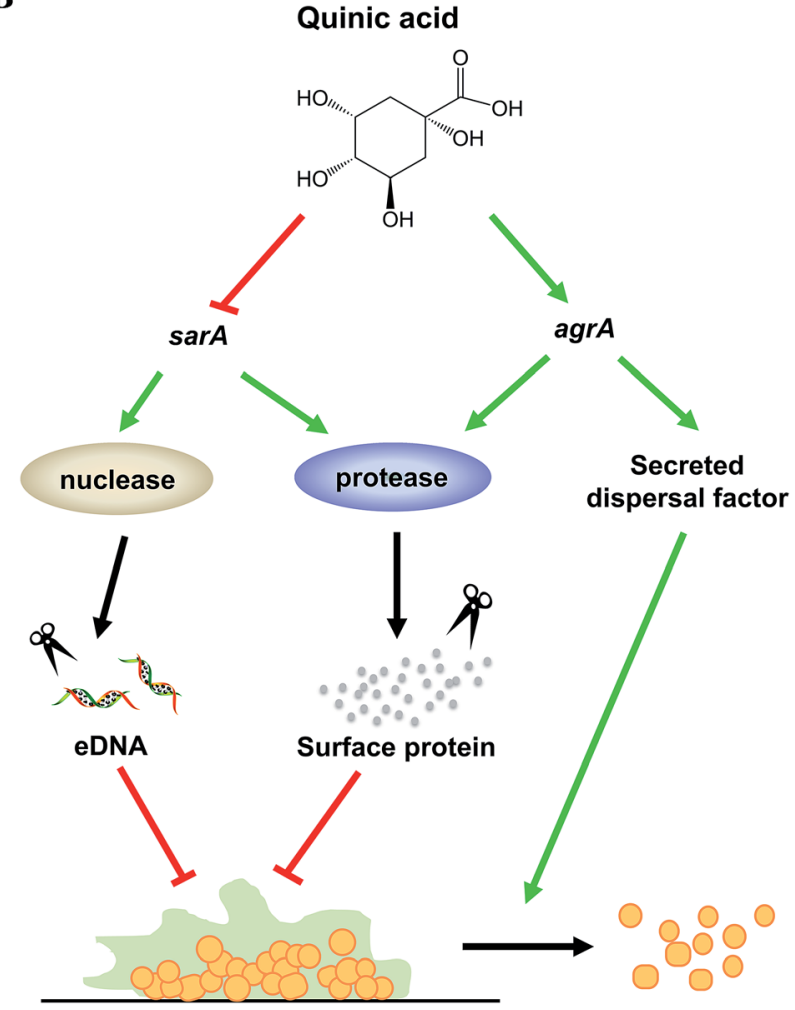

Initial attachment and early multiplication

Planktonic cells

Fig. 5 qRT-PCR results of five related genes (icaR, icaA, sigB, agrA, sarA) in S. aureus ATCC 29213 biofilm formation with $1.25 \mathrm{mg} \mathrm{mL}^{-1}$ of quinic acid treatment (A). Data were expressed as mean \pm standard deviation $(n=3) . * P<0.05, * * P<0.01$, compared with control. A proposed model for regulatory pathway of S. aureus ATCC 29213 biofilm formation in the presence of quinic acid (B).

aureus. ${ }^{14}$ These findings suggested that these organic acids could be as $S$. aureus biofilm inhibitor candidates in food industry. However, the mechanism of their antibiofilm activity remains challenging.

In order to visually confirm the inhibitory action of QA against biofilm formation of $S$. aureus, the micrographs of SEM illustrated the details of the structurally complex matrix

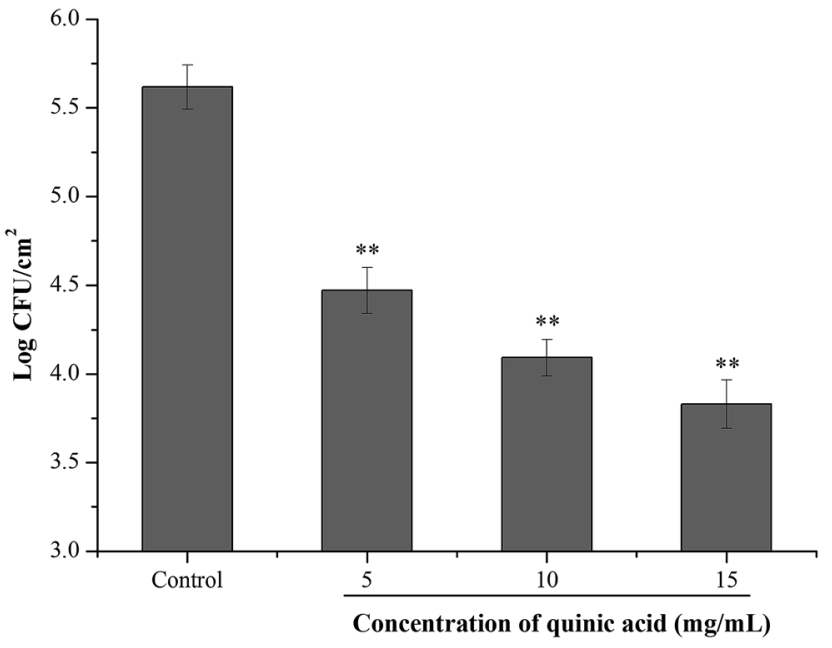

Fig. 6 Effect of quinic acid on the population of S. aureus ATCC 29213 biofilm cells adhered to stainless steel. Data were expressed as mean \pm standard deviation $(n=3)$. $* * P<0.01$, compared with control.

architecture and the bacteria in that matrix. QA treatment led to a huge collapse on the extracellular matrix architecture, resulting in the individual cells and loose microcolonies attached on the glass steel. The images correlated well with the quantitative results of crystal violet staining assay, which indicated that QA possessed a highly antibiofilm activity against $S$. aureus.

During the biofilm formation process, initial adhesion was the first crucial stage, which is mediated by the binding of $S$. aureus of surface anchored protein and host matrix proteins. ${ }^{25}$ Our results showed that QA significantly decreased the initial adhesion of $S$. aureus, which finally resulted in the reduction of biofilm biomass. One possible reason of this action was that QA might destroy the binding proteins and inhibit their activity. ${ }^{20}$ Notably, when treating with $1.25 \mathrm{mg} \mathrm{mL}{ }^{-1}$, the relative percentage adhesion was decreased by approximately $30 \%$, whereas the biofilm biomass was reduced by $72 \%$. This finding suggested that the inhibition of biofilm formation was not absolutely dependent on the inhibition of initial adhesion.

In addition the adhesion ability, the free-floating cells aggregate to form biofilm is influenced by many other physiological factors, such as cell metabolic activity, bacterial viability, cell proliferation and accumulation of multilayer cell clusters. ${ }^{21}$ So, XTT reduction assay was carried out evaluating the effect of QA on the metabolic activity of cells in the S. aureus biofilm. As shown in Fig. 4A, QA significantly decreased the metabolic activity of $S$. aureus biofilm cells. Some studies have proved that the inhibition of biofilm formation was coupled with the decrease of the cell metabolic activity of biofilm..$^{14,26} \mathrm{~A}$ possible reason for such action was that the decrease in metabolic activity was responsible for the resistance of biofilm to antibacterial compounds. ${ }^{27}$ Although XTT assay is a good predictor of the efficacy of antibiofilm compounds, it may have some limitations that it does not always ensure equivalence with cell death. ${ }^{28}$ Hence, we further investigated the cell viability of biofilm by using the LIVE/DEAD Baclight bacterial viability kit. It 
was found that QA not only obviously decreased biofilm biomass but also influenced cell viability of biofilm. When treated with $1.25 \mathrm{mg} \mathrm{mL}^{-1}$ of QA, $S$. aureus biofilm cells showed high number of dead cells. These results revealed that QA was likely to interfere with cell metabolic activity and cell viability of biofilm, and increase the sensitivity of biofilm cells, resulting in the prevention of biofilm formation.

Taken together, the above results suggested that the mechanism of QA against biofilm formation of $S$. aureus may be regulated by multiple pathways. To better understand the mechanism of biofilm formation of $S$. aureus and explore the key regulatory genes in biofilm cells exposed to QA, the transcription levels of genes related to biofilm formation were detected by using qRT-PCR. In $S$. aureus, the SarA, encoded by the gene sarA, is a staphylococcal accessory regulator that is closely related to biofilm adhesion and formation. ${ }^{29}$ As shown in Fig. 5A, the transcription level of sarA was repressed by QA. The gene sarA is necessary during the initial biofilm formation in $S$. aureus and the expression of sarA allows the development of an immature biofilm..$^{30,31}$ sarA mutant was reported to have no ability to form biofilm with increased protease and nuclease activities. ${ }^{30}$ The enhanced activities of protease and nuclease resulted in decreasing production of fibrinogen binding protein and release of eDNA, so as to lead to the inhibition of initial interactions between cell and cell/surface. ${ }^{32}$ This point was also well clarify the reason that QA significantly reduced the adhesion of $S$. aureus to fibrinogen (Fig. 3). In general, the inhibition of QA against biofilm formation was not completely due to the inactivation of sarA, and QA also up-regulated gene agrA, which is a dominant accessory regulator gene. ${ }^{32}$ Previous studies reported that gene agr activation was able to induce dispersion of $S$. aureus cells to planktonic state due to the enhancement of secreted dispersal factors. ${ }^{30,33}$ Moreover, gene $a g r$ can prevent the biofilm initiation, adhesion and maturation through activation of protease and decrease of extracellular matrix proteins. $^{34}$ These phenotypes supported our observation of the relationships between repression of $\operatorname{sar} A$, activation of $\operatorname{agr} A$, and biofilm formation inhibition by QA.

However, in the present study, the biofilm biomass reduction was along with the repression of gene icaR and activation of gene $i c a A$ and $\operatorname{sig} B$. It was contradictory with some previous literatures, which documented that down-regulated of gene icaR could activate gene icaA, leading to the activation of polysaccharide intercellular adhesion and the increase of biofilm biomass, ${ }^{1,32}$ and $S$. aureus mutants in $\operatorname{sig} B$ are unable to form a biofilm. ${ }^{33}$ These contradictory results might be due to the response of different types of $S$. aureus cells to environmental stress caused by various antibacterial agents. A previous study reported that $S$. aureus ica mutants had no reduction in biofilm formation, suggesting that ica was not the crucial factor in certain conditions of biofilm formation. ${ }^{29,32}$ Though gene $\operatorname{sig} B$ was important in the process of biofilm formation, SigB was reported to be a dispensable factor of RNA polymerase that might be activated in stress response. ${ }^{35}$ So, it was suggested that QA could inhibit biofilm formation of $S$. aureus via an ica/sigBindependent pathway.
In light of these results, we concluded that QA was likely to inhibit the initial biofilm formation by acting on the expression of gene sarA and agrA. An inferred model for this regulatory pathway was shown in Fig. 5B, which illustrated that key regulatory genes of QA against $S$. aureus biofilm formation were genes sarA and agrA.

Considering the potential application of QA in the inhibition of $S$. aureus biofilm formation in food processing, the inhibitory effect of QA against $S$. aureus biofilm formation on stainless steel was assessed. Stainless steel is a kind of widely used equipment material in the food industry because of its excellent physicochemical properties, relatively low cost and high resistance to corrosion. ${ }^{36}$ However, the hydrophilic properties of stainless steel provide an advantage for the initial attachment and biofilm formation of bacterial cells. ${ }^{6}$ As shown in Fig. 6, $S$. aureus could adhere in large numbers to stainless steel after a $2 \mathrm{~h}$ of contact. QA at MIC value and higher concentrations were able to significantly decrease the adhered populations of $S$. aureus $(P<0.01)$ after $10 \mathrm{~min}$ treatment. It was noticed that higher concentrations of QA were required to achieve the inhibitory effective against adhered $S$. aureus on stainless steel compared with that used in the biofilm biomass assays. One possible reason is that the population reduction experiment of the adhered bacteria on stainless steel was evaluated using much shorter contact time. Moreover, the sensitivity of planktonic bacteria to antibiofilm compounds is higher than that of adhered bacteria, and the reduction or removal of established biofilm is more difficult than the prevention of biofilm formation. ${ }^{37}$ Hence, strategies to prevent bacterial adhesion and biofilm formation on food or food contact surfaces are important for food industries.

\section{Conclusion}

In conclusion, this was the first time to evaluate the inhibitory activity of QA against biofilm formation of $S$. aureus. QA could effectively inhibit biofilm formation of $S$. aureus at sub-MIC values. QA could prevent the initial biofilm formation by inducing the expression of genes sarA and agrA. The present study suggested that QA was possible to be used on food devices as an antibiofilm agent to prevent biofilm contamination.

\section{Conflicts of interest}

The authors declare that they have no conflict of interest.

\section{Acknowledgements}

This work was financially supported by the National Natural Science Foundation of China (no. 31701574).

\section{References}

1 M. H. Liu, X. X. Wu, J. K. Li, L. Liu, R. G. Zhang, D. Y. Shao and X. D. Du, Food Control, 2017, 73, 613-618.

2 E. Mataraci and S. Dosler, Antimicrob. Agents Chemother., 2012, 56, 6366-6371. 
3 K. B. Ahn, J. E. Baik, C. H. Yun and S. H. Han, Front. Microbiol., 2018, 9, 327.

4 W. Rozemeijer, P. Fink, E. Rojas, C. H. Jones, D. Pavliakova, P. Giardina, E. Murphy, P. Liberator, Q. Jiang, D. Girgenti, R. P. H. Peters, P. H. M. Savelkoul, K. U. Jansen, A. S. Anderson and J. Kluytmans, PLoS One, 2015, 10, e0116945.

5 J. Kadariya, T. C. Smith and D. Thapaliya, Biomed Res. Int., 2014, 2014, 827965.

6 T. Stern, E. Zelinger and Z. Hayouka, Chem. Commun., 2016, 52, 7102-7105.

7 C. Fuente-Núñez, F. Reffuveille, E. F. Haney, S. K. Straus and R. E. W. Hancock, PLoS Pathog., 2014, 10, e1004152.

8 S. H. Lee, L. P. Cappato, C. H. Corassin, A. G. Cruz and C. A. Oliveira, J. Dairy Sci., 2016, 99, 2384-2390.

9 N. A. Al-Shabib, F. M. Husain, I. Ahmad, M. S. Khan, R. A. Khan and J. M. Khan, Food Control, 2017, 79, 325-332.

10 M. M. Theron and F. R. J. Lues, Food Rev. Int., 2007, 23, 141158.

11 M. Y. Akbas and T. Kokumer, Int. J. Food Sci. Technol., 2015, 50, 1666-1672.

12 C. L. Quave, M. Estévezcarmona, C. M. Compadre, G. Hobby, H. Hendrickson, K. E. Beenken and M. S. Smeltzer, PLoS One, 2012, 7, e28737.

13 J. H. Lee, Y. G. Kim, S. Y. Ryu, M. H. Cho and J. Lee, Int. J. Food Microbiol., 2014, 174, 47-55.

14 Ã. Luís, F. Silva, S. Sousa, A. P. Duarte and F. Domingues, Biofouling, 2014, 30, 69-79.

15 N. Cinkilic, S. K. Cetintas, T. Zorlu, O. Vatan, D. Yilmaz, T. Cavas, S. Tunc, L. Ozkan and R. Bilaloglu, Food Chem. Toxicol., 2013, 53, 359-363.

16 S. A. Jang, D. W. Park, J. E. Kwon, H. S. Song, B. Park, H. Jeon, E. H. Sohn, H. J. Koo and S. C. Kang, Biomed. Pharmacother., 2017, 96, 563-571.

17 J. R. Bai, Y. P. Wu, X. Y. Wang, X. Y. Liu, K. Zhong, Y. N. Huang, Y. T. Chen and H. Gao, J. Food Saf., 2018, 38, e12416.

18 J. R. Bai, Y. P. Wu, K. Zhong, K. Xiao, L. J. Liu, Y. N. Huang, Z. S. Wang and H. Gao, J. Food Prot., 2018, 81, 1187-1192.
19 S. Dosler and E. Mataraci, Peptides, 2013, 49, 53-58.

20 D. Ming, D. C. Wang, F. J. Cao, H. Xiang, D. Mu, J. J. Cao, B. B. Li, L. Zhong, X. Y. Dong, X. B. Zhong, L. Wang and T. D. Wang, Front. Microbiol., 2017, 8, 2263.

21 M. Sivaranjani, S. Gowrishankar, A. Kamaladevi, S. K. Pandian, K. Balamurugan and A. V. Ravi, Int. J. Food Microbiol., 2016, 237, 73-82.

22 E. M. Costa, S. Silva, F. K. Tavaria and M. M. Pintado, J. Appl. Microbiol., 2017, 122, 1547-1557.

23 K. Lee, J. H. Lee, S. I. Kim, M. H. Cho and J. Lee, Appl. Microbiol. Biotechnol., 2014, 98, 9447-9457.

24 J. M. Patti, B. L. Allen, M. J. Mcgavin and M. Höök, Annu. Rev. Microbiol., 1994, 48, 585-617.

25 F. Gotz, Mol. Microbiol., 2002, 43, 1367-1378.

26 S. N. Khan, S. Khan, J. Iqbal, R. Khan and A. U. Khan, Front. Microbiol., 2017, 8, 1641.

27 M. M. Bazargani and J. Rohloff, Food Control, 2016, 61, 156164.

28 R. L. Kovács, Z. Tóth, F. Nagy, L. Daróczi, A. Bozó and L. Majoros, J. Appl. Microbiol., 2017, 122, 1529-1536.

29 K. E. Beenken, P. M. Dunman, F. Mcaleese, D. Macapagal, E. Murphy, S. J. Projan, J. S. Blevins and M. S. Smeltzer, J. Bacteriol., 2004, 186, 4665-4684.

30 B. R. Boles and A. R. Horswill, PLoS Pathog., 2008, 4, e1000052.

31 A. I. Doulgeraki, P. Di Ciccio, A. Ianieri and G.-J. E. Nychas, Res. Microbiol., 2017, 168, 1-15.

32 A. E. Paharik and A. R. Horswill, Microbiol. Spectrum, 2016, 4, 1-27.

33 K. J. Lauderdale, B. R. Boles, A. L. Cheung and A. R. Horswill, Infect. Immun., 2009, 77, 1623-1635.

34 J. M. Mootz, C. L. Malone, L. N. Shaw and A. R. Horswill, Infect. Immun., 2013, 81, 3227-3238.

35 I. I. Kullik and P. Giachino, Arch. Microbiol., 1997, 167, 151159.

36 H. R. Van and C. W. Michiels, J. Appl. Microbiol., 2010, 109, 1117-1131.

37 J. Parraruiz, C. Vidaillac, W. E. Rose and M. J. Rybak, Antimicrob. Agents Chemother., 2010, 54, 4329-4334. 